\title{
PAPELAR O PEDAGÓGICO
}

\section{"TO PAPER" THE PEDAGOGIC}

\section{Susana Oliveira Dias}

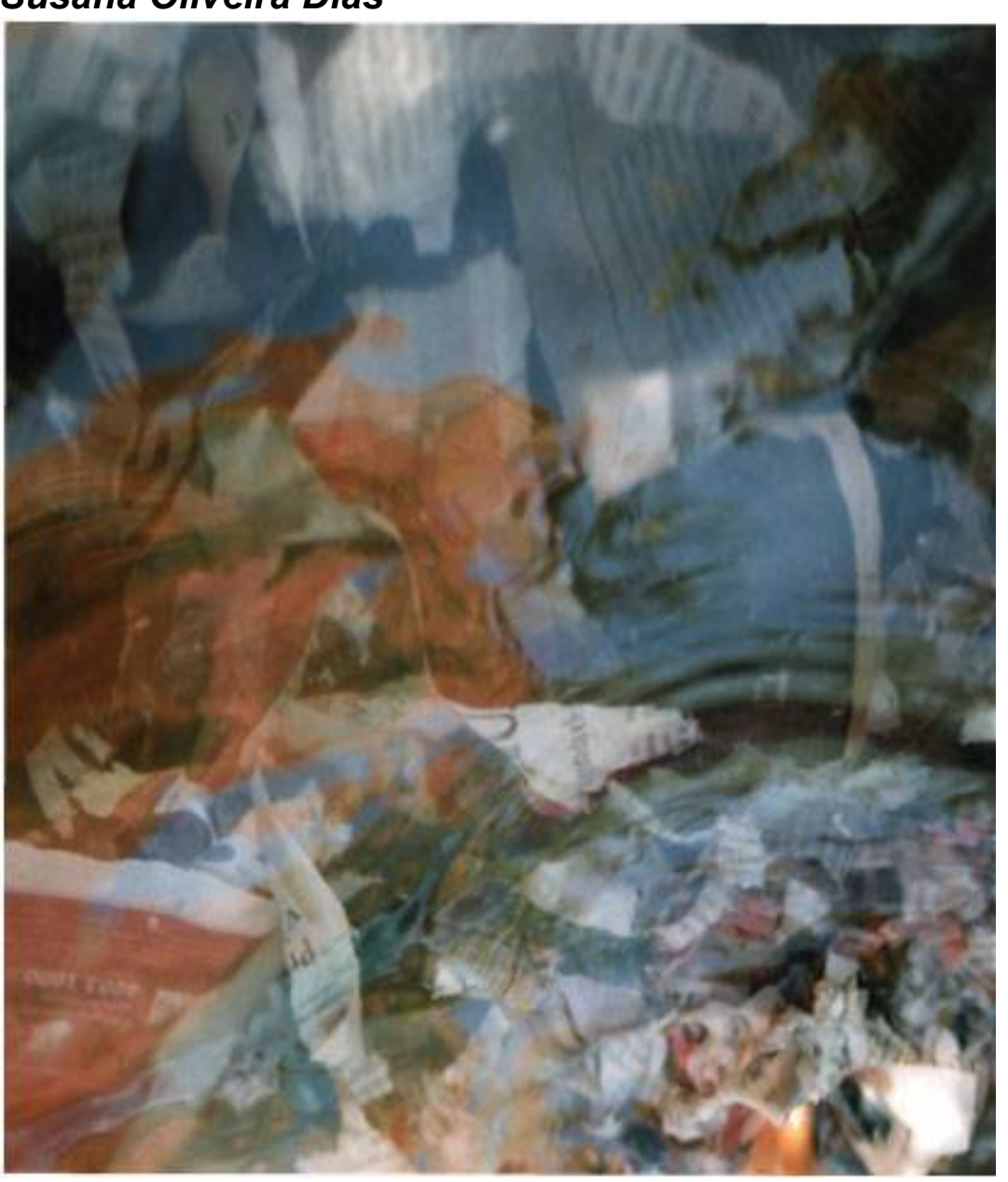

oferecem matérias-tempo em que pulsa a terceira infância que não é do corpo da criança

nem da vivência do filho mas da cria do encontro 
eterno descomeço...

na borda da turba

voam fragmentos

amnesiados de corpo

de um tempo amorfo

sem edição original

no meio do temporal

eterno descomeço...

na dilaceração da forma

a fragilidade da vida

um rasgo no silêncio

faz ver a música

que nos olhos persiste

e para os ouvidos inexiste

"Tudo é d i s p e r s o nada é inteiro"

Fernando Pessoa

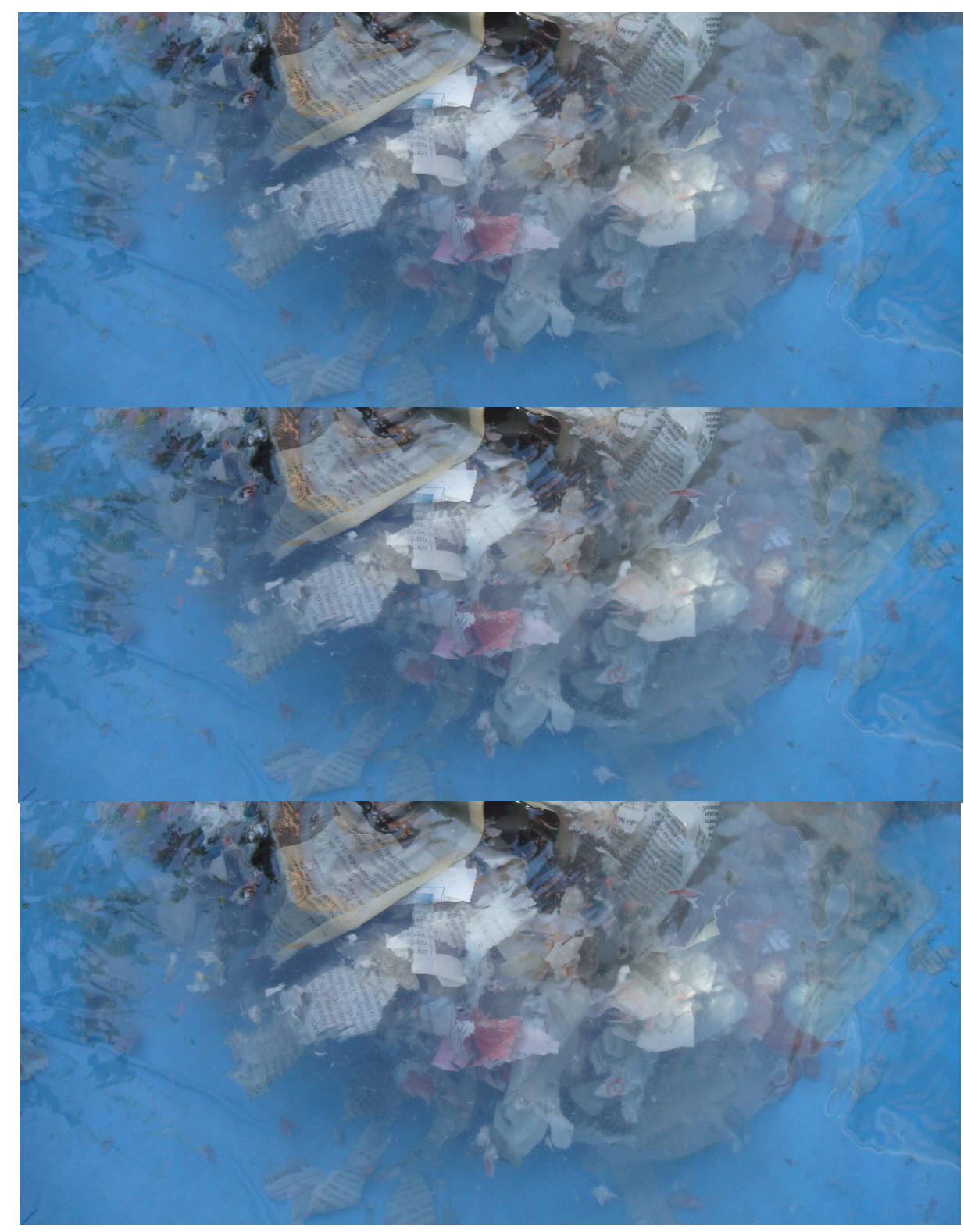




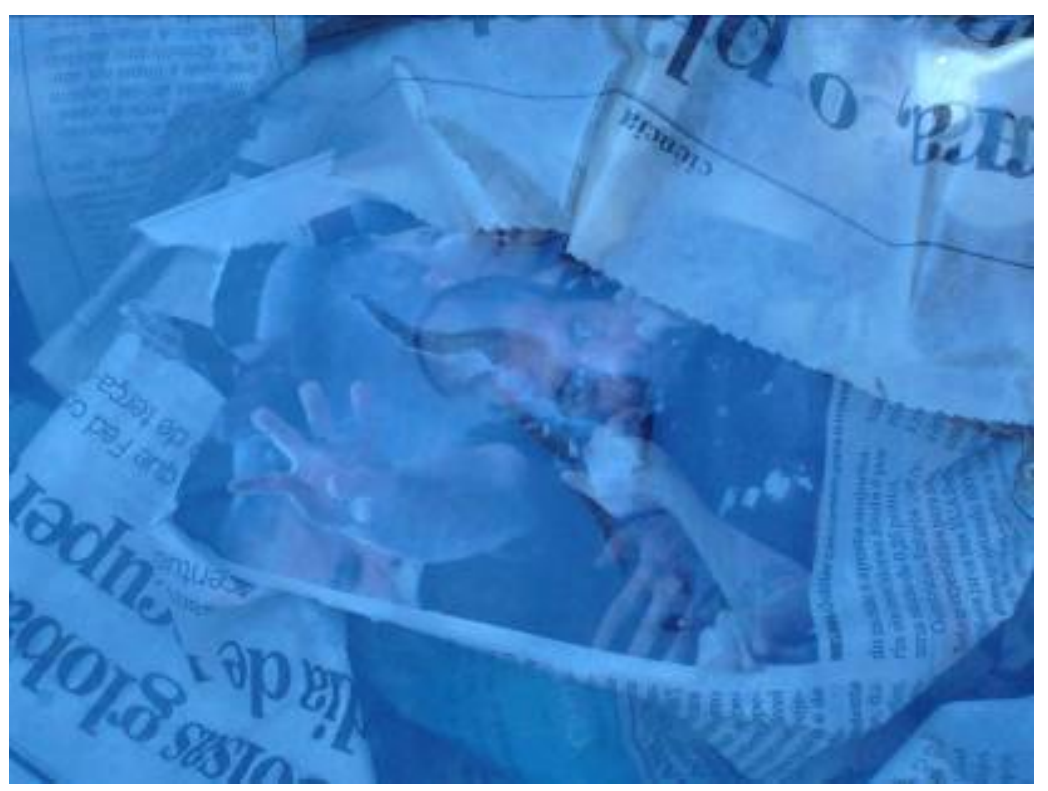

corpo num extremo grito por onde sai um verbo frêmito e ouve-se o tempo

e do denso azul

suscita a dor, a cor,

a voz, a tez

o grito, a morte

convoca forças

foto-gra-vida

e toca a ferida

da vida torturada

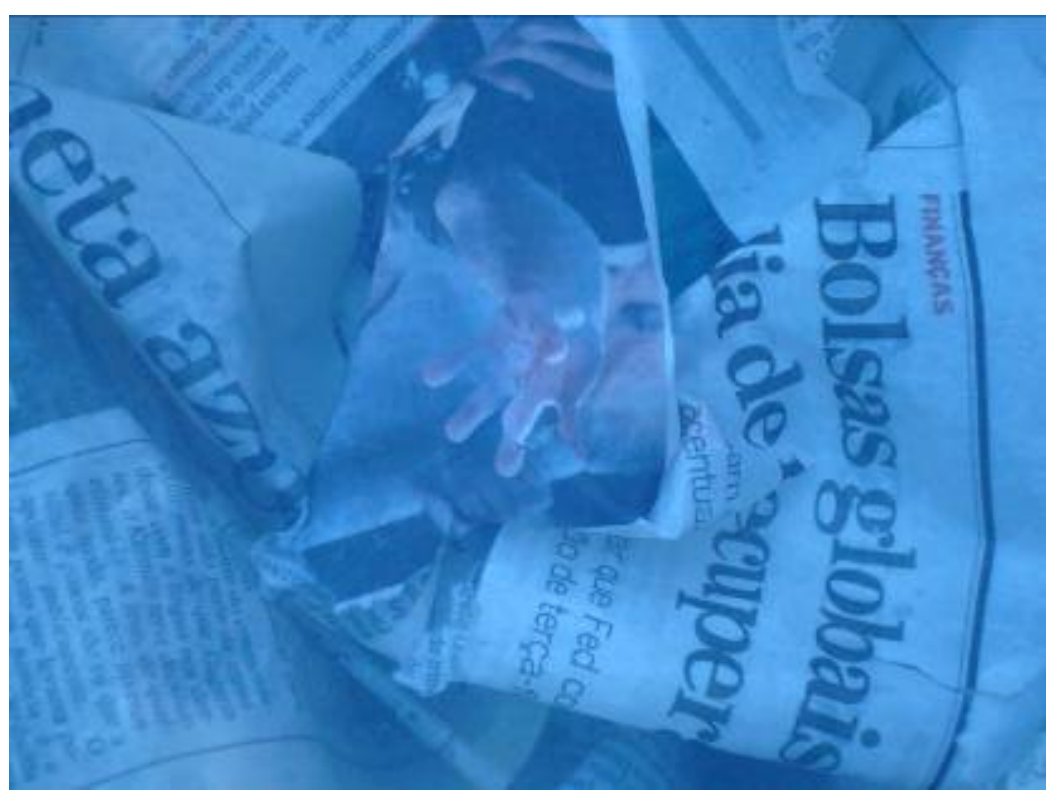




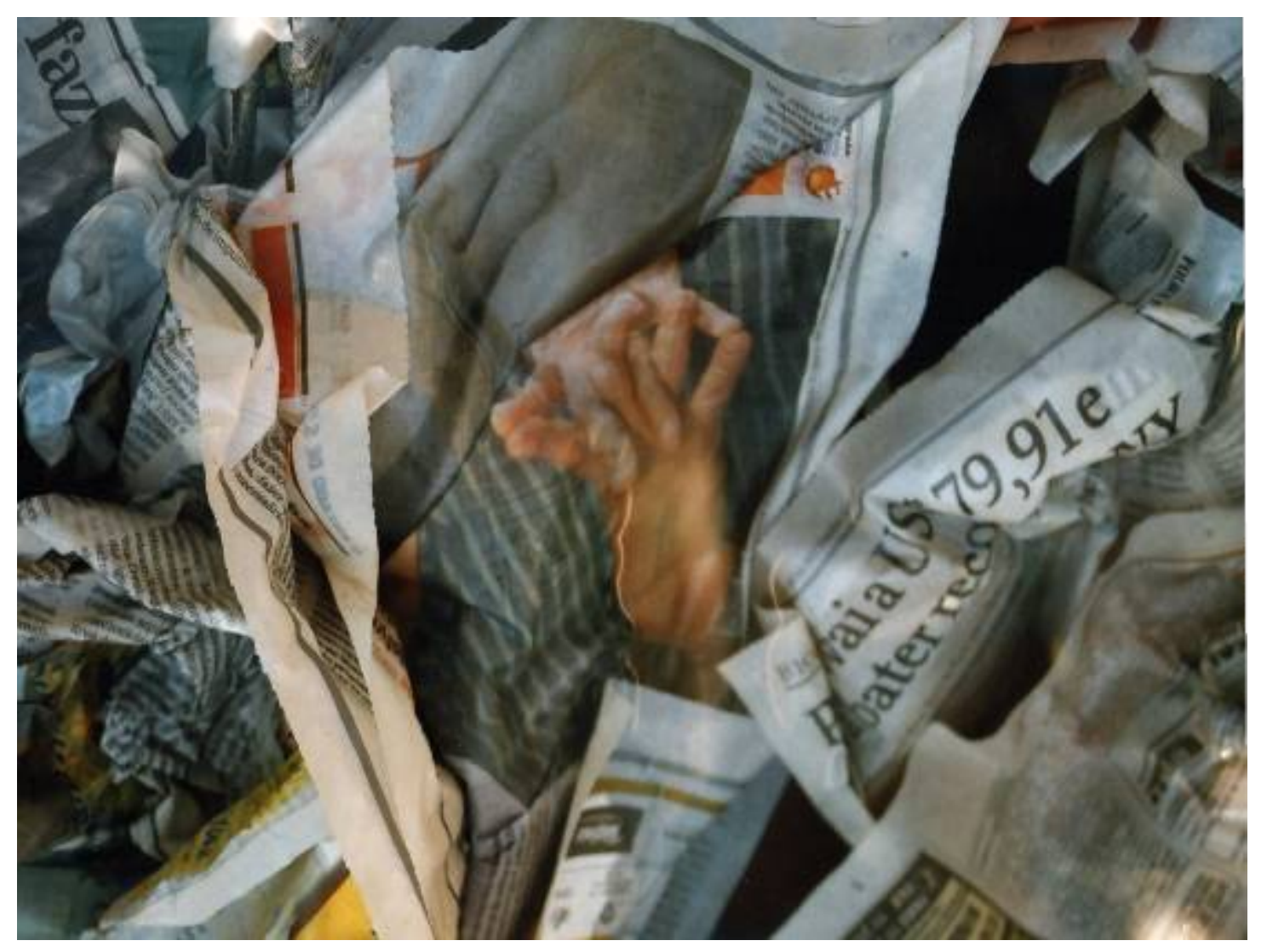

"A vida grita para a morte mas a morte não é esse demasiado-visível que nos faz desfalecer, ela é essa força invisível que a vida detecta, desentoca e faz ver ao gritar" Gilles Deleuze 


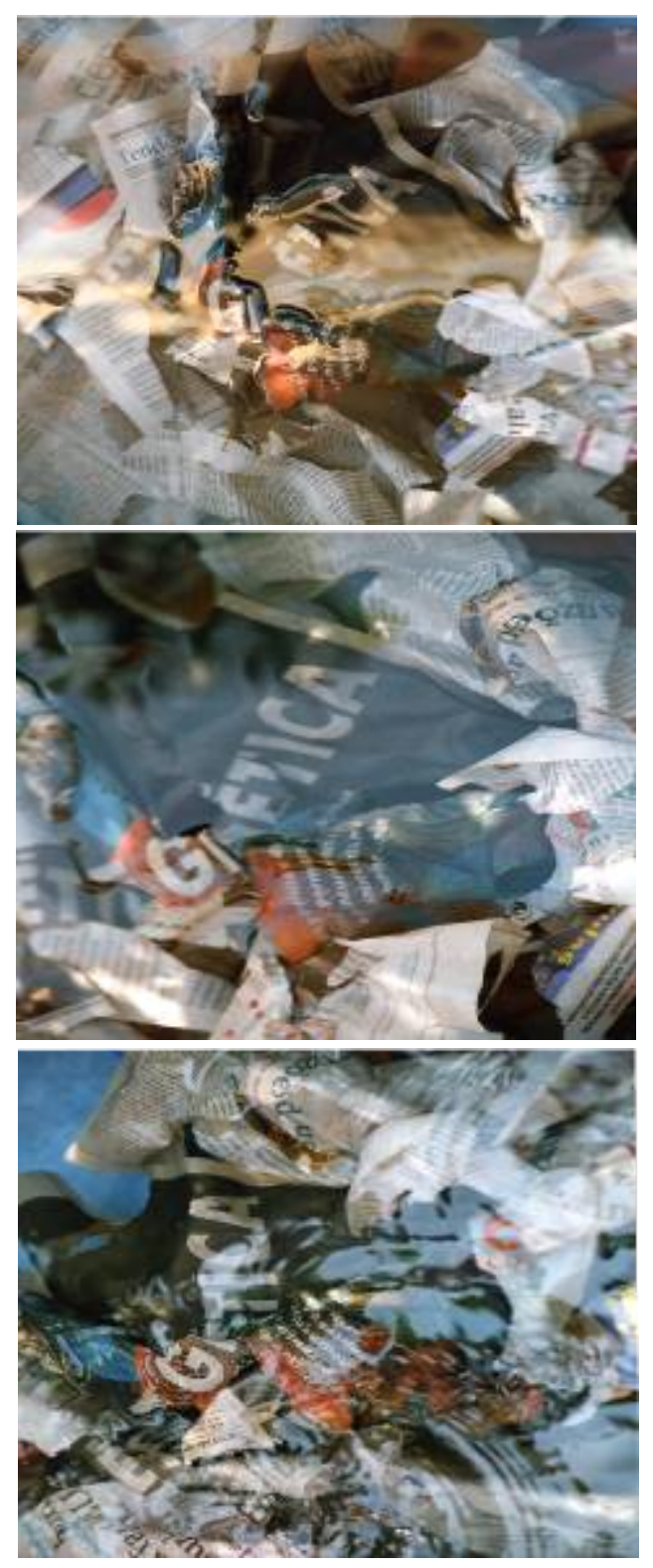

três intensidades

que tremem limites e fronteiras,

e convidam à invasão

de um vento estranho

da oscilação do fogo

de um tempo entranho

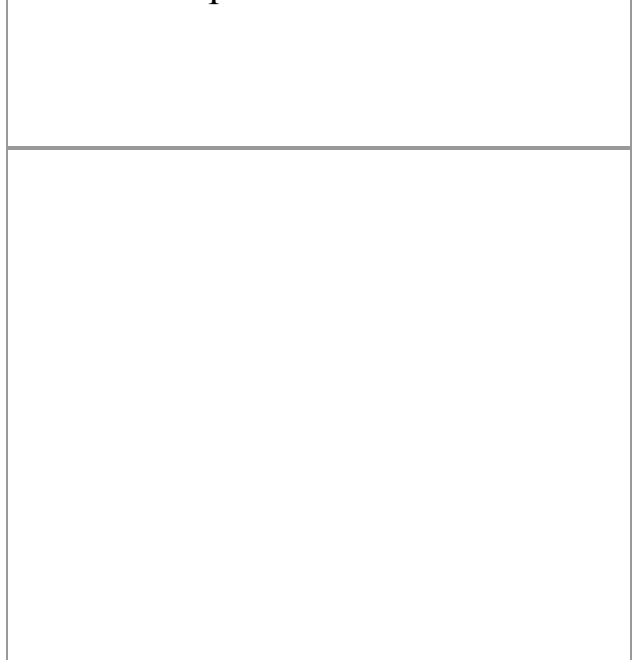

que propagam na superfície

a impossibilidade do ser

ondas do terceiro mundo

que vem com o fora

nascer três variações

que abrem vazios,

brechas, fissuras

muitas freqüências 
"No

osso

da

fala

dos

loucos

tem

lírios"

Manoel

de

Barros

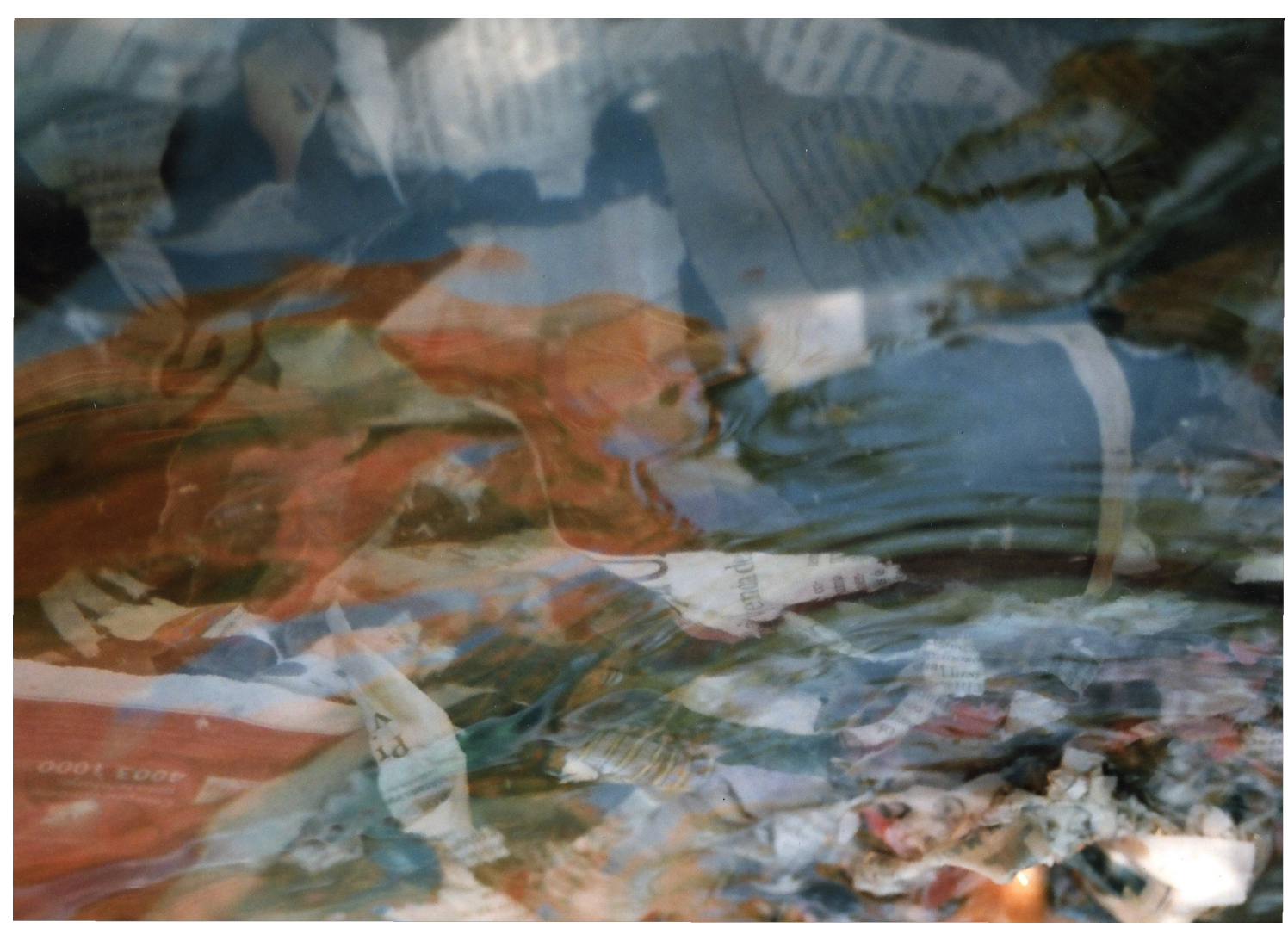

"A loucura é a perda do mundo e de si mesmo a título de um conhecimento sem começo nem fim" Pierre Klossowski apud Deleuze 


\section{REFERÊNCIAS}

BARROS, M. O Guardador de águas. São Paulo: Civilização Brasileira, 1989. Disponível em:

http://www.revistaagulha.nom.br/manu.html. Acesso em: jan. 2008.

DELEUZE, G. Francis Bacon: lógica da sensação. Tradução de Roberto Machado (Coord.). Rio de Janeiro: Jorge Zahar Ed., 2007. Os mistérios de Ariana. Tradução de Edmundo Cordeiro. 2ed. Lisboa: Passagens, 2005.

PESSOA, F. Mensagem. Porto, Portugal: Porto Editora, 2007. (Coleção Mundo das Letras).

\section{CRÉDITOS IMAGENS}

Fotografias de Marli Wunder, 2007. 
ENSAIO

Área Temática: Educação Visual, Linguagens Visuais e Arte

\section{SUSANA OLIVEIRA DIAS}

Pesquisadora e jornalista no Laboratório de Estudos Avançados em Jornalismo (Labjor) da Universidade Estadual de Campinas (Unicamp). Doutora em Educação pela Faculdade de Educação da Unicamp, OLHO. Editora da Revista ComCiência e repórter das revistas Ciência \& Cultura, Inovação e Patrimônio. Tel: (19)35215193.

E-mail: susana@unicamp.br.

Recebido em: 10/03/2008

Publicado em: 20/10/2008 